\title{
Branchioskeletogenital syndrome
}

INSERM

\section{Source}

INSERM. (1999). Orphanet: an online rare disease and orphan drug data base.

Branchioskeletogenital syndrome. ORPHA:1299

Branchioskeletogenital syndrome is a rare multiple congenital anomalies/dysmorphic syndrome characterized by moderate intellectual disability, distinctive craniofacial features (including brachycephaly, facial asymmetry, marked hypertelorism, blepharochalasis, proptosis, a broad nose with concave nasal ridge and bulbous nasal tip, midface hypoplasia, bifid uvula or partial cleft palate, and prognathism), progressive dental anomalies (dentigerous cysts, radicular dentin dysplasia and early tooth loss), vertebral fusions (particularly of C2-C3), and hypospadias. Hearing loss is an additional observed feature. 